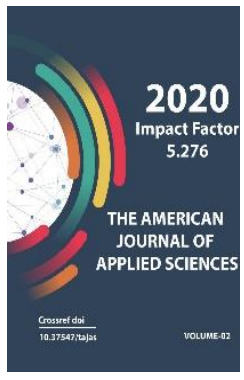

Journal Website: http://usajournalshub.c om/index,php/tajas

Copyright: Original content from this work may be used under the terms of the creative commons attributes 4.0 licence.

\section{The Influence Of Technological Parameters On The Process Of Co2-Extraction Of Biologically Active Substances From Licorice Root}

\author{
Djuraev Kh.F \\ Bukhara Engineering Technological Institute, Bukhara, Uzbekistan \\ Gafurov K.Kh. \\ Bukhara Engineering Technological Institute, Bukhara, Uzbekistan \\ Mukhmadiev B.T. \\ Bukhara Engineering Technological Institute, Bukhara, Uzbekistan \\ Jumaev J. \\ Bukhara State University, Bukhara, Uzbekistan \\ Mirzaeva Sh.U. \\ Bukhara Engineering Technological Institute, Bukhara, Uzbekistan
}

\title{
ABSTRACT
}

The aim of the work is to experimentally study the effect of pressure, temperature and time of supercritical $\mathrm{CO}_{2}$ (SC-CO2) extraction on the yield of extractives from local raw materials - licorice root.

The object of the study was the roots of naked licorice grown in the vicinity of the Bukhara region (border with Turkmenistan).

The experiments were carried out in apparatus for SC-CO2-extraction in the laboratories of the Bukhara Engineering-Technological Institute and the Kuban State Technological University.

The main factors influencing the extraction process of licorice root are taken as follows: $T$-is the temperature of the extractant $(\mathrm{OC}), \tau$ is the duration of extraction ( $\mathrm{min}), \mathrm{P}$ is the pressure of the extractant (MPa).

The experimental conditions were as follows: pressure 7,5-9,5 MPa, temperature from $310 \mathrm{C}$ to $410 \mathrm{C}$, extraction duration 90-150 minutes. The extract yield Yyeld (\%) is taken as the sought function.

The implementation of the intensified process of licorice root extraction is associated with obtaining calculated equations that allow determining the duration of the extraction process and rational parameters of the extraction mode. For this purpose, we have applied the method of planning multifactor experiments. 
A generalized equation has been determined that describes the process of $\mathrm{CO}_{2}$ extraction of licorice roots, with the help of which it is possible to reveal the degree of influence of each investigated factor (extractant temperature, process duration, extractant pressure) on the final result, which is necessary to optimize the process.

\section{KEYWORDS}

Planning multifactor experiments, biologically active substances, licorice root, extraction, extract, supercritical carbon dioxide, pressure, temperature, extraction time.

\section{INTRODUCTION}

Licorice (Glycyrrhizaglabra L.) is a perennial shrub of the legume family that grows mainly in Central Asia, the Middle East and Southeastern Europe. Since ancient times, dried licorice roots have been widely used as a food flavoring agent and for various medicinal purposes $[1,2,3,4,5,6]$.

There are about 13 types of licorice root in the world. The most common types are: naked licorice (Glycyrrhizaglabra), Ural licorice (Glycyrrhizauralensis Fisch) and Korzhinsky licorice (Glycyrrhizae Korshinskyi Grig). Naked licorice is the most popular among them, its roots contain the largest amount of biologically active substances (BAS) $[7,8,9,10]$. The quality of licorice root is standardized by the State Pharmacopoeia: the content of extractive substances (ES) extracted by $0,25 \%$ ammonium hydroxide solution must be at least $25 \%$, moisture no more than $14 \%$, ash no more than $8 \%$, glycyrrhizic acid (GA) - no less $6 \%$ $[11,12,13,14]$. GA is the most valuable extractable substance; however, licorice root contains other biologically active substances: up to $5,0 \%$ of flavonoids, carbohydrates up to $34,0 \%$, proteins up to $10,1 \%$, amino acids up to $12,71 \%$, including asparagine up to $4,0 \%$, fats and fat-like substances up to $4,7 \%$, ascorbic acid up to $3,1 \%[15,16,17]$.

Known technology of extraction of licorice root [18], in which the extraction consists in the process of bimaceration with $0,25 \%$ aqueous ammonia solution with a modulus of 1: 5 for 48 hours, the second time - with a threefold amount for 24 hours.

In the conditions of specialized liquorice factories, the hood is obtained using a battery of diffusers operating on the counterflow principle. Extraction is carried out with hot water [19]. The technological sequence for the production of licorice root extract is as follows: grinding; extraction in batch diffusers; filtration; evaporation of juices in boilers; thickening of the extract in the evaporator of the I-group; thickening of the extract in an evaporator of the II-group; packaging, labeling, storage.

The disadvantage of these technologies is the low yield of the extract, the long duration and energy consumption of the process. 


\section{MATERIALS AND METHODS}

There is a vacuum-pulse technology for processing licorice root. The principle of operation of this extraction [20] is based on preliminary degassing of raw materials under vacuum, impregnation with an extractant under atmospheric pressure, periodic heating, followed by impulse evacuation to a residual pressure equal to the vapor pressure of the solvent at a given temperature, and connection with atmospheric pressure. As a result of impulse evacuation, the solvent boils up in the pores of the material, and the resulting vapor pushes the extractant saturated with the target component into the volume of the miscella. Then, when combined with the atmosphere, fresh portions of the solvent enter the pores of the material. The above sequence of actions is repeated as many times as necessary.

The use of ammonia in this technology creates some technical problems, since it, being an aggressive medium, will volatilize during evacuation and adversely affect pumps, the inner surface of pipelines, receivers. In addition, its inevitable emissions into the environment are unacceptable.

In work [21], the ammonia solution in vacuumpulse extraction was replaced by sodium hydroxide, which is not subject to evaporation. The extraction time of licorice root at a temperature of $60^{\circ} \mathrm{C}$, an alkali concentration of $0,5 \%$ of the mass. and in a pulse mode with a cycle of 10 minutes does not exceed two hours. Prospective for extraction is the use of carbon dioxide in subcritical regions (at pressures below 7,39 $\mathrm{MPa}$ ) (liquefied state) and supercritical regions (compressed state), the so-called $\mathrm{CO}_{2}$-extraction. Carbon dioxide goes into a supercritical state at critical temperature
$(31,30 \mathrm{C})$ and pressure $(7,39 \mathrm{MPa})$. In this state, the substance expands, occupying the entire provided volume, like a gas, but has a high density, like a liquid. Thus, supercritical $\mathrm{CO}_{2}$ can, in principle, better than a classical solvent penetrate into the material to be extracted, absorb and transport dissolved components $[22,23,24]$.

In [25], supercritical extraction with carbon dioxide ( $\left.\mathrm{SC}-\mathrm{CO}_{2}\right)$ of glycyrrhizin from licorice root was performed. The composition of the solvent and the particle size were investigated in order to obtain the maximum yield. The optimal extraction conditions were as follows: pressure $30 \mathrm{MPa}$; temperature $50^{\circ} \mathrm{C} ; \mathrm{CO}_{2}$ consumption about $10 \mathrm{~kg} / \mathrm{h}$; particle size $0,3-$ $0,4 \mathrm{~mm}$. The SC-CO2 extraction was better than traditional extraction, ultrasonic extraction, microwave extraction and so on.

Traditionally, licorice root is most actively grown (due to climatic features) in the northwest of Uzbekistan - in Karakalpakstan and the Khorezm region. According to foreign experts, licorice root is mainly exported in the form of raw materials $[26,27]$. Therefore, the technological processing of this local valuable medicinal raw material and the production of a $\mathrm{CO} 2$ extract is urgent. CO2-extract is a concentrate of the plant's own substances, free of impurities, solvents and water, obtained using carbon dioxide as a solvent.

The aim of this work is to experimentally study the influence of pressure, temperature, and time of $\mathrm{CO}_{2}$-extraction on the yield of extractives from local raw materials - licorice root.

Materials and methods. The object of the study was the roots of naked licorice grown in the vicinity of the Bukhara region (border with 
Turkmenistan). The quality of the roots meets the requirements of GOST 22839-88 Roots and rhizomes of licorice. Technical conditions. Licorice roots and rhizomes. Specifications. The yield of the obtained extract was determined according to the requirements of GOST 22840-77 (date of update of the description: 06.01.2019) Licorice root extract. Technical conditions. Extract of licorice root. Specifications.

The licorice roots were cut into strips and ground in an electric mill to a size of $0,6-0,8$ $\mathrm{mm}$. The experiments were carried out on laboratory facilities, the description of which is given in $[28,29]$.

The implementation of the intensified process of licorice root extraction is associated with obtaining calculated equations that allow determining the duration of the extraction process and rational parameters of the extraction mode. For this purpose, we applied the method of planning multifactor experiments $[34,35,36,37]$.

Experimental planning methods allow the most economical and efficient way to obtain mathematical models of the investigated process in the realized range of changes in many factors influencing the process.
It is possible to get a clear idea about the place of planning experiments if we consider the general scheme of paired experimental research of an object with an insufficiently clarified mechanism of the processes occurring in this object.

\section{EXPERIMENTAL PART}

The main factors influencing the extraction process of licorice root are taken as follows: $T$ is the temperature of the extractant $(O C), \tau$ - is the duration of extraction (min), $\mathrm{P}$ - is the pressure of the extractant (MPa).

The limits of variation of the factors are selected based on the analysis of the results of preliminary experiments to study the process of $\mathrm{CO}_{2}$ extraction of plant materials.

The extract yield Yyeld (\%) is taken as the sought function.

In our case, when the number of factors is three, when implementing the experimental plan, according to [34], it is necessary to carry out 15 experiments, varying the factors at five levels.

Allocation of factors and levels of their variation is presented in table. 1.

\section{Tab. 1. Levels of the studied factors}

\begin{tabular}{|c|c|c|c|c|c|c|}
\hline \multirow{2}{*}{ № } & Factors & \multicolumn{5}{c|}{ Levels } \\
\cline { 3 - 7 } & & $\mathbf{1}$ & $\mathbf{2}$ & $\mathbf{3}$ & $\mathbf{4}$ & $\mathbf{5}$ \\
\hline 1 & Extractant temperature, $\mathrm{T}\left(\mathrm{C}^{\circ}\right)$ & 31 & 33 & 35 & 38 & 41 \\
\hline 2 & Extraction time, $\tau(\mathrm{мин)}$ & 90 & 105 & 120 & 135 & 150 \\
\hline 3 & Extractant pressure, $\mathrm{P}(\mathrm{MПа)}$ & 7,5 & 8,0 & 8,5 & 9,0 & 9,5 \\
\hline
\end{tabular}




\section{RESULT AND DISCUSSION}

Experimental results. The implementation of the $5 \times 3$ experiment plan with the values of the factors is presented in table. 2 .

Tab. 2. Results of the experiment plan reproduction

\begin{tabular}{|c|c|c|c|c|}
\hline № & $\mathrm{T}\left(\mathrm{C}^{0}\right)$ & $\tau(\min )$ & $\mathrm{P}(\mathrm{MPa})$ & $Y_{\text {yeld, }} \%$ \\
\hline 1 & 31 & 90 & 7,5 & 26,6 \\
\hline 2 & 31 & 105 & 8 & 28,7 \\
\hline 3 & 31 & 120 & 8,5 & 32,4 \\
\hline 4 & 31 & 135 & 9 & 33,2 \\
\hline 5 & 31 & 150 & 9,5 & 34,4 \\
\hline 1 & 35 & 90 & 8,5 & 28,1 \\
\hline 2 & 35 & 105 & 9 & 33,7 \\
\hline 3 & 35 & 120 & 9,5 & 31,6 \\
\hline 4 & 35 & 135 & 7,5 & 30,4 \\
\hline 5 & 35 & 150 & 8 & 34,7 \\
\hline 1 & 33 & 90 & 9,5 & 33,9 \\
\hline 2 & 33 & 105 & 7,5 & 26,7 \\
\hline 3 & 33 & 120 & 9 & 34,1 \\
\hline 4 & 33 & 135 & 8,5 & 33,2 \\
\hline 5 & 33 & 150 & 8 & 31,4 \\
\hline 1 & 41 & 90 & 8 & 28,4 \\
\hline 2 & 41 & 105 & 8,5 & 29,9 \\
\hline 3 & 41 & 120 & 9 & 31,2 \\
\hline 4 & 41 & 135 & 9,5 & 34,4 \\
\hline 5 & 41 & 150 & 7,5 & 33,8 \\
\hline
\end{tabular}


The American Journal of Applied Sciences (ISSN - 2689-0992)

Published: September 30, 2020 | Pages: 273-286

Doi: https://doi.org/10.37547/tajas/Volume02Issue09-38

\begin{tabular}{|c|c|c|c|c|}
\hline № & $\mathrm{T}\left(\mathrm{C}^{\circ}\right)$ & $\tau(\mathrm{min})$ & $\mathrm{P}(\mathrm{MPa})$ & $\mathrm{Y}_{\text {yeld, }}$ \\
\hline 1 & 38 & 90 & 9 & 31,6 \\
2 & 38 & 105 & 9,5 & 32,8 \\
3 & 38 & 120 & 7,5 & 28,7 \\
4 & 38 & 135 & 8 & 31,4 \\
5 & 38 & 150 & 8,5 & 33,5 \\
\hline
\end{tabular}

The structure of the matrix is such that during all experiments, each level of any factor meets once with each level of all other factors, for this each level of each factor is set in the experiments as many times as the levels are accepted. This achieves the averaged effect of any factor, i.e. The same effect is provided that occurs with an infinitely large number of experiments with a random variation of all factors. This opens up the possibility of applying the methods of mathematical statistics and achieves savings in the number of experiments [34].
From table. 3 it can be seen that the average values of the five levels of each function are equal to the general average: Yav.yeld $=32,5 \%$. The coincidence of the mean with the total mean is a criterion for the absence of errors in calculations.

Empirical formulas for the formulation of partial dependences of the extract yield, final temperature and final pressure depending on the extraction parameters, initial moisture content of plant material, temperature and $\mathrm{CO} 2$ flow rate were obtained as a result of data processing by the least squares method $[34,38]$.

Tab. 3. Experimental values of partial functions

\begin{tabular}{|c|c|c|c|c|c|c|}
\hline \multirow{2}{*}{ Functions } & \multicolumn{5}{|c|}{ Levels } & Average \\
\cline { 2 - 6 } & $\mathbf{1}$ & $\mathbf{2}$ & $\mathbf{3}$ & $\mathbf{4}$ & $\mathbf{5}$ & value \\
\hline $\mathrm{Y}_{1}(\mathrm{~T})$ & 31,92 & 33,04 & 33,32 & 33,18 & 32,02 & 32,5 \\
\hline $\mathrm{Y}_{2}(\tau)$ & 30,6 & 32,64 & 32,7 & 33,38 & 33,16 & 32,5 \\
\hline $\mathrm{Y}_{3}(\mathrm{P})$ & 31,7 & 31,84 & 32,14 & 32,78 & 34,02 & 32,5 \\
\hline
\end{tabular}

Formulas and calculated values of partial functions are presented in Table 4. 
Tab. 4. Calculated values of partial functions

\begin{tabular}{|c|c|c|c|c|c|c|}
\hline \multirow{2}{*}{ Functions } & \multicolumn{5}{|c|}{ Levels } & Average \\
\cline { 2 - 6 } & 1 & 2 & 3 & 4 & 5 & value \\
\hline$y=41,772+4,176 \cdot x-0,058 \cdot x^{2}$ & 31,98 & 32,9 & 33,38 & 33,2 & 32,0 & 32,6 \\
\hline$y=10,537+0,336 \cdot x-0,0001 \cdot x^{2}$ & 30,77 & 32,19 & 33,05 & 33,3 & 33,11 & 32,5 \\
& & & & 6 & & \\
\hline$y=75,080-0,2211 \cdot x+7257 \cdot x^{2}$ & 31,74 & 31,76 & 32,13 & 32,87 & 33,97 & 32,5 \\
\hline
\end{tabular}

Graphs of dependences of the extract yield on influencing factors are shown in Fig. 1-3.

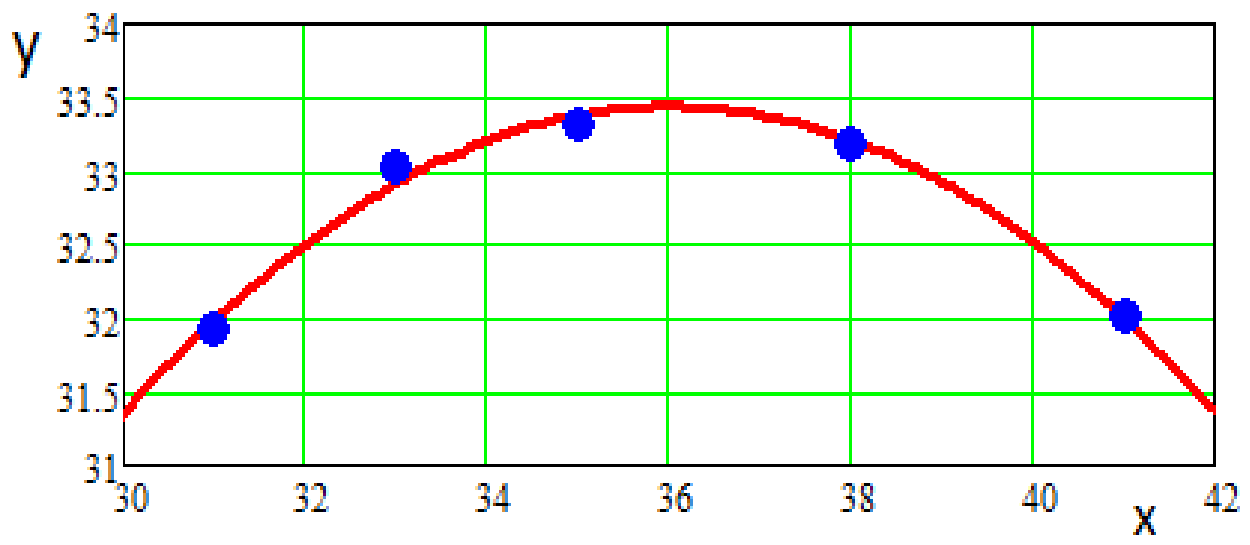

Fig. 1. Dependence of the extract yield on the effect of temperature according to the model

$$
y=-0.058 \cdot x^{2}+4.176 \cdot x+41.772
$$


Points - are experimental data

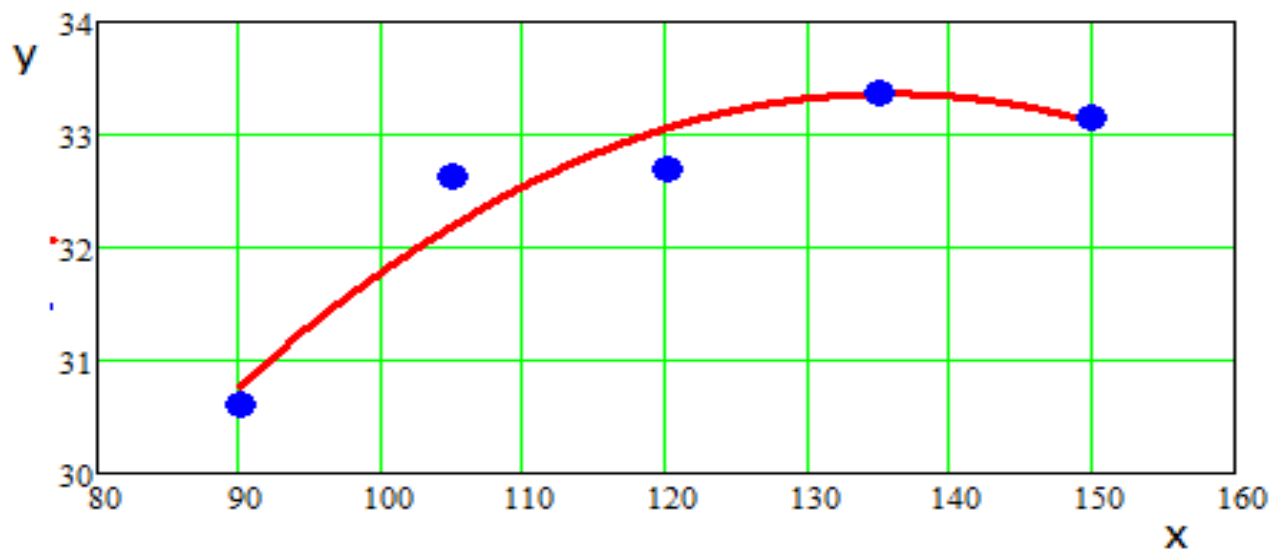

Fig. 2. Dependence of the extract yield on the influence of the extraction time according to the model

$$
\begin{aligned}
& y=-0.0001 \cdot x^{2}+0.336 \cdot x+10.537 \\
& \text { Points - are experimental data }
\end{aligned}
$$

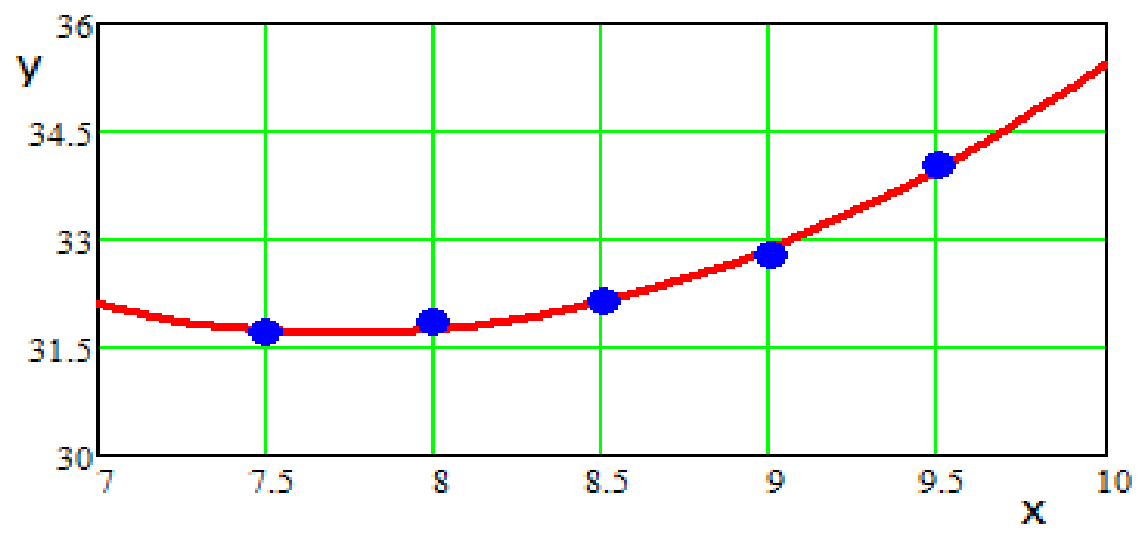

Fig. 3. Dependence of the extract yield on the influence of model pressure

$$
\begin{aligned}
& \mathbf{y}=\mathbf{0 . 7 2 5 7} \cdot \mathbf{x}^{2}-\mathbf{0 . 2 2 1 1} \cdot \mathbf{x}+\mathbf{7 5 . 0 8} \\
& \text { Points - are experimental data }
\end{aligned}
$$

Determination of the significance of private functions. In order to make a judgment about the degree of validity of the adopted parameters, we determined their significance. In accordance with 
the provisions of mathematical statistics and probability theory, functions describing the process are divided into significant and insignificant. If the function is insignificant, then the interval of its change does not go beyond the admissible scatter of experimental data, i.e. is within the confidence interval.

We determine the significance of partial dependence functions using the coefficient of nonlinear multiplier correlation R [34]:

$$
R=\sqrt{1-\frac{(N-1) \cdot \sum_{1}^{N}\left(Y_{e x p}-Y_{c a l}\right)^{2}}{(N-k-1) \cdot \sum_{1}^{N}\left(Y_{e x p}-Y_{a v}\right)^{2}}}
$$

where $\mathrm{N}$ - is the number of described points $(\mathrm{N}=5) ; \mathrm{k}$ - is the number of operating factors ( $\mathrm{k}$ = 1); $Y_{\exp }$ - experimental result; $Y_{c a l}$ - theoretical (calculated) result; $Y_{a v}$ - average experimental value.

Tab. 5. Values calculated from calculated data

\begin{tabular}{|c|c|c|c|c|c|c|}
\hline \multirow{2}{*}{ Functions } & \multicolumn{5}{|c|}{ Levels } & \multirow{2}{*}{ Amount } \\
\cline { 2 - 6 } & 1 & 2 & 3 & 4 & 5 & \\
\hline$(T)=\left(Y_{\text {exp }}-Y_{\text {cal }}\right)^{2}$ & 0,0322 & 0,1594 & 0,025 & 0,0084 & 0,0658 & 0,2908 \\
\hline$(P)=\left(Y_{\text {exp }}-Y_{\text {cal }}\right)^{2}$ & 0,0278 & 0,2038 & 0,1247 & 0,0003 & 0,0024 & 0,0718 \\
\hline$(\tau)=\left(Y_{\text {exp }}-Y_{\text {cal }}\right)^{2}$ & 0,0019 & 0,0069 & 0,0005 & 0,0086 & 0,0020 & 0,019452 \\
\hline
\end{tabular}

Table 6. Values calculated from the average calculated data

\begin{tabular}{|l|c|c|c|c|c|c|}
\hline \multirow{2}{*}{ Functions } & \multicolumn{5}{|c|}{ Levels } & \multirow{2}{*}{ Amount } \\
\cline { 2 - 6 } & 1 & 2 & 3 & 4 & 5 & \\
\hline$(T)=\left(Y_{\exp }-Y_{a v}\right)^{2}$ & 0,6 & 0,1183 & 0,3893 & 0,2342 & 0,4569 & 1,8 \\
\hline$(P)=\left(Y_{\ni}-Y_{a v}\right)^{2}$ & 2,9899 & 0,0945 & 0,3104 & 0,7475 & 0,378 & 4,52 \\
\hline$(\tau)=\left(Y_{\ni}-Y_{a v}\right)^{2}$ & 0,9920 & 0,7327 & 0,3091 & 0,0071 & 1,7530 & 3,7939 \\
\hline
\end{tabular}

The significance is determined by the formula [34]: 


$$
t_{R}=\frac{R \sqrt{N-k-1}}{1-R^{2}}
$$

The values of the correlation coefficients $R$ and its significance $t_{R}$ are given in Table 7 .

Tab. 7. Correlation coefficient $R$ and its significance $t_{R}$ for partial functions

\begin{tabular}{|c|c|c|c|}
\hline Function & $\mathbf{R}$ & $\mathbf{t}_{\mathbf{R}}$ & Function value \\
\hline$Y_{1}(T)$ & 0,988 & $73,5>2$ & significant \\
$Y_{2}(P)$ & 0,95 & $15,46>2$ & significant \\
$Y_{3}(\tau)$ & 0,99 & $237>2$ & significant \\
& & & \\
\hline
\end{tabular}

To obtain the equation of the technological process of $\mathrm{CO}_{2}$ - extraction of licorice roots, the formula proposed by M.M. Protodyakonov [34]:

$$
Y_{P}=\frac{\prod_{i=1}^{n} Y_{i}}{Y_{a v}^{n-1}}
$$

where $Y p$ - is a generalized function; $Y_{i}$ - is a partial function; $\prod_{i=1}^{n} Y_{i}$ - product of partial functions; $Y_{a v}^{n-1}$ - the total average of all the values of the generalized function taken into account, in power by one less than the number of partial functions.

According to formula (3), generalized equations describing the process of supercritical $\mathrm{CO}_{2}$ extraction of licorice roots are defined:

$$
Y_{\text {yeld }}=\frac{\left(41,772+4,176 \cdot x-0,058 \cdot x^{2}\right) *\left(10,537+0,336 \cdot x-0,0001 \cdot x^{2}\right)}{32,49^{2} *\left(75,080-0,2211 \cdot x+7257 \cdot x^{2}\right)^{-1}}
$$

The inference results and ratios (4) are presented in table 8. 
Tab. 8 Inference Results and relations (4)

\begin{tabular}{|c|c|c|c|c|c|}
\hline $\mathrm{Y}_{\text {yeld, }} \%$ & $\mathrm{Y}_{\mathrm{cal}}$ & $\left|Y_{\text {exp }}-Y_{\text {cal }}\right|$ & $\left|Y_{\text {exp }}-Y_{a v}\right|$ & $\left|Y_{\exp }-Y_{\text {cal }}\right|^{2}$ & $\left|Y_{\text {exp }}-Y_{a v}\right|^{2}$ \\
\hline 26,6 & 31,38 & 3,70 & 5,89 & 13,70 & 34,69 \\
\hline 31,7 & 32,49 & 0,42 & 0,79 & 0,17 & 0,62 \\
\hline 31,4 & 31,93 & 0,79 & 1,09 & 0,63 & 1,18 \\
\hline 35,5 & 33,61 & 1,02 & 3,01 & 1,05 & 9,06 \\
\hline 34,4 & 33,05 & 0,01 & 1,91 & 0,0002 & 3,64 \\
\hline 31,6 & 32,49 & 0,37 & 0,89 & 0,13 & 0,79 \\
\hline 32,7 & 31,93 & 1,28 & 0,21 & 1,64 & 0,04 \\
\hline 35,2 & 33,61 & 1,47 & 2,71 & 2,17 & 7,34 \\
\hline 32,4 & 33,05 & 1,33 & 0,09 & 1,78 & 0,008 \\
\hline 34,7 & 31,38 & 2,18 & 2,21 & 4,77 & 4,88 \\
\hline 31,9 & 31,93 & 1,13 & 0,59 & 1,28 & 0,34 \\
\hline 34,6 & 33,61 & 1,45 & 2,11 & 2,12 & 4,45 \\
\hline 34,1 & 33,05 & 0,85 & 1,61 & 0,73 & 2,59 \\
\hline 33,2 & 31,38 & 1,09 & 0,71 & 1,20 & 0,50 \\
\hline 31,4 & 32,49 & 2,35 & 1,09 & 5,52 & 1,18 \\
\hline 31,3 & 33,61 & 0,79 & 1,19 & 0,63 & 1,41 \\
\hline 31,4 & 33,05 & 0,91 & 1,09 & 0,83 & 1,18 \\
\hline 31,2 & 31,38 & 0,08 & 1,29 & 0,007 & 1,66 \\
\hline 34,4 & 32,496 & 1,43 & 1,91 & 2,07 & 3,64 \\
\hline 31,8 & 31,938 & 1,08 & 0,69 & 1,18 & 0,47 \\
\hline 31,6 & 33,054 & 0,06 & 0,89 & 0,004 & 0,79 \\
\hline 32,8 & 31,38 & 2,03 & 0,31 & 4,12 & 0,09 \\
\hline 31,6 & 32,496 & 0,89 & 0,89 & 0,81 & 0,79 \\
\hline
\end{tabular}


The American Journal of Applied Sciences

(ISSN - 2689-0992)

Published: September 30, 2020 | Pages: 273-286

Doi: https://doi.org/10.37547/tajas/Volume02Issue09-38

2020: 5.276

\begin{tabular}{|c|c|c|c|c|c|}
\hline$Y_{\text {yeld, }} \%$ & $Y_{\text {cal }}$ & $\left|Y_{\text {exp }}-Y_{\text {cal }}\right|$ & $\left|Y_{\exp }-Y_{\text {av }}\right|$ & $\left|Y_{\text {exp }}-Y_{\text {cal }}\right|^{2}$ & $\left|Y_{\text {exp }}-Y_{\text {av }}\right|^{2}$ \\
\hline 31,4 & 31,938 & 1,09 & 1,09 & 1,19 & 1,18 \\
\hline 33,5 & 33,612 & 1,21 & 1,01 & 1,47 & 1,02 \\
\hline
\end{tabular}

Based on the tabular data, the correlation coefficients for the generalized equation (4) are found.

For equation (4), the correlation coefficient for temperature $T$ is $R=0,67$ and its significance $t R$ $=2,105$, for pressure $R=0,77$ and its significance $t R=3,386$, for the extraction time $R=0,87$ and its significance $t R=2,012$. The data presented indicate the adequacy of the generalized equation (4).

\section{CONCLUSIONS}

The resulting equation (4) makes it possible to determine with sufficient accuracy the yield of extractives from licorice roots of local origin under the conditions of SC-CO2-extraction in the investigated range of changes in factors. Using equation (4), it is possible to identify the degree of influence of each investigated factor (extractant temperature, process duration, extractant pressure) on the final result, which is necessary to optimize the process.

\section{REFERENCES}

1. Tzu-Chien Kao, Chi-Hao Wu, and Gow-Chin Yen. Bioactivity and Potential Health Benefits of Licorice // Journal of Agricultural and Food Chemistry. 2014, 62, 3, P. 542-553

2. Avicenna's Journal of Phytomedicine. Electronic resource: https://docksci.com/antibacterial-activityof-glycyrrhiza-glabra-against-oral- pathogens-an-in-vitro-

_5ac92976d64ab29fo6f3199c.html

3. Licorice root: a powerful antiviral, antimicrobial and antifungal agent. Electronic resource: https://www.botanicalmedicine.org/licorice -root-antiviral-antimicrobial-antifungal/ published on November 25, 2019.

4. K.Kh. Gafurov, B.T. Mukhammadiev, Sh.U. Mirzaeva Supercritical [SC] $\mathrm{CO}_{2}$ extraction of glycyrrhizic acid from licorice roots, Chemical Journal of Kazakhstan ", No. 2, 2016, P. 169-176.

5. BT Mukhammadiev, Sh.U. Mirzaeva, F.S. Kuldosheva Chemical composition of licorice (licorice), XI International Scientific and Technical Conference Technique and Technology of Food Production Abstracts, Mogilev, 2019, P. 210.

6. H.F. Djuraev, K.Kh. Gafurov, B.T. Mukhammadiev, Sh.U. Mirzaeva, Obtaining glycyrrhizic acid from licorice root by extraction, Journal "Development of science and technology" Bukhara Institute of Engineering Technology No. 1, 2020, P. 80-84.

7. Yin, G .; Cao, L .; Xu, P .; Jeney, G .; Nakao, M .; Lu, C. Hepatoprotective and antioxidant e_ects of Glycyrrhizaglabra extract against carbon tetrachloride $\left(\mathrm{CCl}_{4}\right)$-induced hepatocyte damage in common carp (Cyprinuscarpio). Fish Physiol. Biochem. 2011, 37, 209-216. [CrossRef] [PubMed]

8. Vlaisavljevi'c, S .; Šibul, F .; Sinka, I .; Zupko, I ; Ocsovszki, I .; Jovanovi'c-Šanta, S. 
Chemical composition, antioxidant and anticancer activity of licorice from Fruska Gora locality. Ind. Crop. Prod. 2018, 112, P. 217-224. [CrossRef]

9. Guo, Y .; Tong, Z .; Tong, P .; Sun, J. Pilot study on treatment process of licorice products wastewater. China Water Wast. 2010, 26, P. 58-62.

10. Tolstikov, G.A. Licorice: biodiversity, chemistry, applications in medicine / G.A. Tolstikov, G.A. Baltina, L.A. Grankina, R. M. Kondratenko, T. G. Tolstikova. - Novosibirsk: Publishing house of the Novosibirsk Institute of Organic Chemistry, 2007. - P. 314.

11. Electronic resource: http://farmacomua.narod.ru/licorice

12. Rezenkova, O. V. Study of the influence of licorice extract on the processes of adaptation of the body: dis. ... Cand. biol. Sciences: 03.00.13 / Rezenkova Olga Vladimirovna. - Stavropol, 2003. P-175.

13. Monographs on medicinal plants widely used in the newly independent states (NIS) [Electronic resource]. -WHO, 2010. -P.464 Access mode: http://www.who.int/medicines/areas/traditi onal/monograph_russian.pdf

14. Egorov, M.V. Standardization of raw materials and preparations of licorice: dis.... Cand. farm. Sciences: 15.00.02 / Egorov Maxim Valerievich. - Perm, 2005 .-P. 145.

15. Rules for the collection and drying of medicinal plants: a collection of instructions // M .: Medicine. - 1985. - P.232-236.

16. Ramaswami, S .; Behrendt, J .; Gulyas, H .; Otterpohl, R. Pretreatment of wastewater from licorice processing - Apreliminary evaluation. Water Environ. Res. 2016, 88, 2032-2039. [CrossRef] [PubMed]

17. Jin, Q .; Yang, L. C .; Poe, N .; Huang, H.B. Integrated processing of plant-derived waste to produce value-addedproducts based on the biorefinery concept. Trends Food Sci. Technol. 2018, 74, -P. 119-131. [CrossRef]

18. Muravyov I.A. Drug technology. Ed. 3rd, rev. and add. T. 1.M., 1980. -P. 704.

19. Kadyrova R.Kh. Improvement of the process of evaporation of licorice root extract // Dissertation for the degree of candidate of technical sciences, Moscow, 1990, -P. 9-10.

20. RF patent №2163827. Method for extracting materials / Abramov Y.K. et al. 2001

21. Rybalchenko A.S., Golitsyn V.P., Komarova L.F. Study of the extraction of licorice root // Chemistry of vegetable raw materials. 2002. No. 4. -P. 55-59.

22. Koshevoy E.P. Extraction with carbon dioxide in food technology / E.P. Koshevoy, Kh.R. Blyagoz. - Maikop, 2000, P. 495.

23. Kasyanov G.I. Theory of gas-liquid technologies // Electronic resource: http://krkgi.ru/glav/co2tech/index.htm

24. McHugh M. A., Krukonis V. J., Supercritical fluid extraction: principles and practice, Boston, 1986.

25. Wei Wei, Jianzhong Yin, Che Zhu, Yi Liu, Wenhua Shi. Supercritical Carbon Dioxide Extraction of Glycyrrhizin from Licorice Root // 7th Italian Conference of Supercritical Fluids and Their Applications. Electronic resource: https://mafiadoc.com/supercritical-carbondioxide-extraction-of-glycyrrhizin-fromlicoriceroot_5b815a56097c4729598b4611.html

26. Licorice root in Karakalpakstan. Electronic resource:

https://uz.sputniknews.ru/economy/2017011 2/4582550/koren-solodki-v-

karakalpakstane.html

27. Growth of the raw material base and the depth of processing of licorice root. Electronic 
http://agronews.uz/ru/information/rastenie vodstvo/ lekarstvennye-rasteniya / 844-rostsyrevoj-bazy-i-glubiny-pererabotkisolodkovogo-kornya

28. Gafurov K., Kh., Ibragimov U. M., Fayziev Sh.l. Statistical-mathematical model of the process of extraction of pumpkin seeds by CO2-extraction // Austrian Journal of Technical and Natural Sciences. \# 1-2 2017. P.59-63.

29. Kasyanov G.I., Medvedev A.M., Gafurov K.Kh. Ways of using carbon dioxide as a solvent // Scientific and technical journal "Development of Science and Technology". 2019 No. 5. -P.54-59.

30. Mukhamadiev BT, Gafurov K.Kh., Sh.U. Mirzaeva, Sharipova MF, The rate of lipid extraction from melon seeds with supercritical $\mathrm{CO}_{2}$ with a co-solvent, Chemical Journal of Kazakhstan ", No. 2, 2016. -P.169-176.

31. K.Kh. Gafurov, B.T. Mukhammadiev, K.E. Ruzieva, V.N.Akhmedov, Modeling of different modes of extraction with the ethanol $+\mathrm{CO}_{2}$ solvent system, Scientific journal, Scientist of the XXI century 1-3,2017, -P. 44-47.

32. K.Kh.Gafurov, B.T.Mukhammadiev, Sh.U. Mirzaeva, Production ingredients from plant raw materials by $\mathrm{CO} 2$ extruction, Lambert Academic Publishing, Monograph, 2018.

33. H.F. Dzhuraev, K.Kh. Gafurov, B.T. Mukhammadiev, Sh.U. Mirzaeva, Comparative analysis of the effect of pressure and temperature on the process of supercritical $\mathrm{CO}_{2}$-extraction of plant raw materials, Butlerov Communications No 7 , volume 55. 2018, Tatarstan, P. 109-113.

34. V.P. Malyshev Mathematical planning of metallurgical and chemical experiments. Alma-Ata: Nauka, 1977.-P. 36.
35. 35.Sh.U. Mirzaeva, Extraction of Glycyrrhizic Acid from Licorice Root using $\mathrm{CO}_{2}$, International Journal of Advanced Research in Science, Engineering and Technology Volume 6, Issue 4, April 2019, India, - P. 8939-8946.

36. H.F. Djuraev, K.Kh. Gafurov, B.T. Mukhammadiev, Sh.U. Mirzaeva, Supercritical $\mathrm{CO}_{2}$ extraction of glycyrrhizic acid from licorice root: optimization of extraction conditions using RSM (response surface metodology), Science News of Kazakhstan, scientific and technical journal, Kazakhstan, No. 4, 2019, -P. 55- 72.

37. K.Kh. Gafurov, B.T. Mukhammadiev, Sh.U. Mirzaeva, F.S. Kuldosheva, Obtaining extracts from plant raw materials using carbon dioxide, Food Science and Technology, Scientific and Production Journal Odessa, Volume 14 No. 1 (2020), P. 47-53.

38. Johnson N., Lyon F. Statistics and experimental planning in technology and science. M. Publishing house. "Mir", 1981, P. 146-160. 